\title{
Obesity and health care interventions: Substantiating a multi-modal challenge through the lens of grounded theory
}

\author{
Milind Mandlik $^{1}$ (D) | John G. Oetzel ${ }^{2}$ | Djavlonbek Kadirov ${ }^{3}$
}

${ }^{1}$ Department of Marketing, University of Auckland Business School, Auckland, New Zealand

${ }^{2}$ Waikato Management School, University of Waikato, Hamilton, New Zealand

${ }^{3}$ The School of Marketing and International Business, Victoria University of Wellington, Wellington, New Zealand

\section{Correspondence}

Milind Mandlik, Department of Marketing, University of Auckland Business School, Auckland 1010, New Zealand.

Email:m.mandlik@auckland.ac.nz

Handling Editor: Louise Signal

\begin{abstract}
Issue addressed: One of the biggest concerns for human health in the 21st century is the ever-increasing rate of obesity and its associated budgetary implications for publicly funded health care service provisioning. This study at the outset explores the multifaceted nature of food-related consumption choices and outcomes of obesity, and later offers suggestions to improve the existing interventional strategies to curtail the epidemic.
\end{abstract}

Methods: A total of 24 participants were recruited through poster invitations placed around the greater metropolitan area of Auckland, New Zealand. Participants shared their health care intervention program experiences through in-depth, semi-structured interviews. Data were analysed in keeping with traditions of constructivist grounded theory.

Findings: Analysis revealed various concurrent individually acting and ecologically mediated processes which led to obesogenic outcomes as a result of social actors' (participants) engagement in acts of (food-related) consumption practices.

Conclusions: This study helps to illustrate the underlying, multifaceted processes that lead to obese individuals feeling defeated or disempowered and categorically willing, yet unable to bring about healthy changes in their lives. We hope this study will prompt health care practitioners to take a holistic approach while conceiving and deploying health care intervention programs.

So what?: Current health care interventional programs are not achieving optimum solutions for those in need. All future programs need to acknowledge the roles played by an individual, as well as ecological factors, while deploying client-centric intervention solutions. Perhaps these programs are in need of a team-based approach to offer a truly "wrap-around" service provisioning strategy, rather than the traditional oneon-one consultative approaches in use at current times.

\section{KEYWORDS}

food marketing, grounded theory, health care intervention, health promotion, obesity, wellbeing 


\section{1 | INTRODUCTION}

Health care intervention programs designed to assist in resolving issues of obesity management (weight loss programs) have become a worldwide industry. The industry is expected to become a $\$ 200$ billion industry by the end of $2020 .^{1}$ Although the number of individuals participating in these programs has grown significantly, the upsurges in obesity rates do not show any signs of slowing down. These programs are generally sought by individuals seeking control on the quality of life indicators such as improved life expectancy, self-reported health status, and self-reported mental and emotional well-being. ${ }^{2}$ These programs are mostly designed and delivered, by skilled professionals such as doctors, nutritionists, pharmacists, naturopaths, fitness consultants and dieticians, to name a few. The programs are deployed as combinations of one-on-one consultations, which generally include recommendations for lifestyle modifications, meal-replacement strategies and suggestions for engaging in varying degrees of physical activity.

It is well documented that some of the challenges associated with current patterns of food consumption and the consequences of obesity go beyond the needs of satiation of hunger. ${ }^{5,6}$ As a case in point, years of research and investment in health-promotive programs have had limited success in curtailing the growing obesity epidemic. ${ }^{7,8}$ As a case in point, at 12 months, a randomised trial of low-fat and low-carbohydrate meal replacement program resulted in participants losing no more than $2 \%-4 \%$ of their body weight, with some participants losing very minimal amounts. This enduring challenge of obesity cannot be simply viewed as an individual or communal issue; it has far-reaching consequences for the socio-economic fabric of many nations. Some of the immediate concerns pertain to the resultant loss of productivity and the net impact on publicly funded health care expenditures of an economy. ${ }^{9}$

More and more obese individuals are actively engaging with a range of health care intervention programs to remedy the status quo, but they often fail to achieve healthy changes in their lives. These individuals seem more like defeated (disempowered) entities as they seem to have given up on their quest for a better quality of life. ${ }^{10-12}$ The "Foresight Obesity Project" has previously outlined how exploring the obesity epidemic could be a monumental challenge in itself. ${ }^{13}$ Yet this study wanted to capture the lived experiences of participants as they embarked on their personal journeys towards healthy living with the help of interventional programs.

Studies show most intervention programs demonstrate high to moderate dropout rates or disengagement rates. ${ }^{14,15}$ It is observed that during the initial stages of such programs individuals tend to lose modest amounts of weight; however, these individuals do not remain engaged in the programs long enough to achieve their desired outcomes (ie weight loss). ${ }^{16}$ Most commercially offered intervention programs put the onus on individuals to make the required behavioural changes for achieving healthy outcomes. This means most programs rely on commitments at the individual level for an optimal outcome. In addition, studies have shown interventions that depend solely on an individual's willpower (self-discipline) are destined to fail, owing to a variety of psychological, socio-economic, cultural and physiological causes. ${ }^{17}$

This grounded theory-based research enquiry was initiated to explore the multi-level complexities associated with obesity management, particularly for those individuals who were willingly engaged in health care intervention programs, yet were having limited success for their efforts. The fundamental research question guiding this study was: How do individuals experience and negotiate food-related consumption choices and associated obesogenic outcomes within the context of health care intervention programs?

Our findings suggest a variety of individual as well as ecological mediators of obesity work in tandem to produce the resultant outcomes and hence were beyond the realm of individual willpower alone. Our results suggest many of these multi-level mediators, in fact, are so intertwined in an individual's routine life, that unpacking them en route to solution-seeking remains a challenge in itself. We propose future delivery of any intervention program needs to take a holistic view of the challenges faced by each seeking assistance and perhaps needs to customise the program to fit individual needs. Our results categorically showed obesogenic consequences, as an outcome of food-related consumption practices, eventually gave rise to pronounced feelings of vulnerability and a sense of helplessness for most study participants. The narratives suggest no matter how hard participants tried to make healthy changes to their lifestyles (through interventions), their efforts either yielded limited success or resulted in further weight gain, giving rise to pronounced feelings of perpetual entrapment. These findings were particularly helpful in outlining a key set of recommendations for practitioners engaged in designing and delivering intervention programs.

\section{2 | METHODS}

The constructivist grounded theory was deployed in this study, which allowed for a fully immersive data-gathering experience during interview sessions with participants. ${ }^{18}$ It offered a unique opportunity for the research team and participants to co-create various openended experiences (or episodes) of knowledge sharing. This version of grounded theory also encourages the researcher to become part of the induction-abduction-deduction process, where the knowledge always remains a co-created outcome. ${ }^{18,19}$ The research team comprised three researchers who were assigned different roles within the project. The data were collected, transcribed and coded by the team leader. Later on, the line-by-line analysis was done as a team, usually through note (memo) sharing during face-to-face or Skype meetings over a period of 2 years. The methodology, as well as the method, worked well with the relativist ontological stance of the lead researcher.

Study participants were considered for inclusion based on two specific criteria: (a) participants had previously engaged with or were currently engaged with health care intervention programs; and (b) participants were willing to articulate their experiences in written and spoken English during interview sessions. In total, 24 participants (13 female and 11 male) were interviewed over a period of 18 months. The youngest participant was 21 years old, and the 
oldest was just over 60 years old, and participants had come from all walks of life. Obese outcomes were as much an issue for economically well-off as well as for those participants who were living in low-income communities within the city. Most of them were residing within the greater metropolitan region of Auckland, New Zealand. Auckland is a multi-cultural and multi-ethnic city, so each participant had a different story to share. Participant confidentiality was maintained via assigning pseudonyms to all participants.

After ethics approval was granted by the Human Research Ethics Committee (Univerisyt of Waikato), the immediate sampling strategy focussed on recruiting a purposive sample, participants were invited to take part in a research interview through poster advertisements. The research interviews were initially guided by a set of predetermined themes, which were approved by the ethics committee. As the interview processes evolved, new themes were added to the interview guide. Intense interviewing is one of the preferred methods for data collection in constructivist grounded theory. The method promotes an in-depth and often intimate discussion of the participant's experiences which goes beyond the normal limits of conversational etiquette. Intense interviewing can be classified as an interaction which is controlled, flexible, emergent, co-created and designed to elicit deep-seated insights from the participant. ${ }^{18,20}$ Each interview began after participant's signed a consent form. Following interviews, interview data were transcribed, transcript accuracy was validated by participants, coding and memo writing were completed, and data analysis conducted through a process of constant comparison. Memo writing was initiated from the outset of the enquiry and continued until analysis was completed. Memos were intermittently shared and discussed with the entire team to seek opinions and feedback regarding the authenticity of the sociological processes that were emerging from the data.

The focus of data analysis was to illustrate the underlying social processes that captured food-related consumption choices, as well as how participants were re-living (or describing) the episodes of their subsequent engagements with health care intervention programs. Interview transcripts were coded line-by-line using gerunds as dictated by standard practice for coding under the tradition of constructivist grounded theory. ${ }^{18}$ This led to substantive or open coding, through which concepts, dimensions and properties of raw data were revealed. This process was continued until theoretical saturation was achieved. The process of coding and analysis was greatly assisted by data management software NVivo. ${ }^{10}$ To ensure credibility that study claims were factual and derived from the data, we consistently used participant narratives in determining and presenting the findings. After each interview, participants were given an opportunity to review the transcripts, which was done to make sure that the interview had in fact captured the narratives in their totality.

\section{3 | RESULTS}

The findings of this study are essentially comprised of six major processes: competing priorities, migration, feelings of vulnerability, socio-cultural normativity, pervasive food marketing and intervention setbacks. These six processes collectively lead to feelings of helplessness for most study participants. The findings are organised in a way to initially outline three major processes which influenced consumption choices not only at an individual level but also at an ecological level. The remaining three major processes demonstratively acted through ecological influences alone, collectively leading to feelings of perpetual entrapment. The subtle differences between individually acting and ecologically mediated processes can be explained better by contextualising them with the help of a participant narrative. The case of Alwyna demonstrates these subtle differences by highlighting how she was affected at an individual level as well as at an ecological level (Table 1).

It is evident that these simultaneously acting processes were able to entrap Alwyna into a pattern of a repeated cycle of excessive food consumption she could not walk away from. The subsequent discussion will summarise all of the major processes and sub-processes with the help of participant narratives, starting with the three major processes and sub-processes that had influence at both individual and ecological levels.

\section{1 | Competing priorities}

Competing priorities outlines the processes that make it difficult for individuals to prioritise personal health over other competing urgencies in life which sometimes subsumed the mental and physical resources needed for achieving personal health and well-being. Findings showed that for many individuals, prioritising personal health and well-being over everything else in their lives was not an easy task. This major process is elaborated further with the help of three distinct sub-processes: ease of access, socio-economic pressures and stressful lives.

Ease of access to foods was discussed by a few participants who noted the impact that their busy lifestyles and their consistent access to abundant food sources had on their health. This ease of access, when coupled with other stressors in life, made for situations that were even more counterproductive to health and well-being. In addition, it was not just the ease of access, but also a lack thereof that was a contributing factor to ill health. The sub-process of socio-economic pressures represents externally driven stressors which had a significant impact on family meal choices. Many participants noted that often when there was a shortfall in resources needed (funds) to procure food, the healthiness of food ceased to be a priority in their consumption choices. A few of the participants also explained that buying unhealthy foods was much more economical than buying healthy foods such as fresh fruit and vegetables, but they still bought more economical, unhealthy foods knowing full well that the consequences of those choices for their health and well-being. Socio-economic triggers of consumption choices and consequences of obesity have been studied for more than two decades. ${ }^{21,22}$ In fact, studies have shown socio-economic status can lead to fractured ability to make 
healthy consumption choices and seemingly has intergenerational consequences. ${ }^{23,24}$ The third sub-process of stressful lives describes how a lack of time to focus on healthy consumption choices put participants in situations that were counterproductive to their own health. Rodney, a single father, described how a departmental promotion put him in a stressful team environment that proved to be detrimental to his health.

Again, I think a contributing factor was work. I was head of the department at the time; stress, a lot of stuff going on, you know, politics within. And my doctor would say to me: "Why do you work in that place?" ... at that point was the point at which I realised ... I had to change. (Rodney, M-51)

Stress in itself causes the human body to prepare for a flight or fight response, and in so doing, the body stores every bit of energy it consumes, generally as fat cells, for when it might be needed for survival in times of uncertainty. This efficient storage of energy is the precursor for weight gain and subsequent obesity. ${ }^{25,26}$ Our findings suggest living a healthy lifestyle is not as easy as it seems when it is a balancing act to prioritise health over everything else in life. There are a variety of individual and circumstantial stressors that eat away at the very resources individuals need to look after themselves. Data analysis further revealed yet another issue closely connected to altered food-related consumption practices titled: migration.

\subsection{Migration}

Migration processes in this study are elaborated further by two distinct sub-processes: migrating to new foods and overwhelming new foods. Migrating to new foods describes the experiences of participants who moved countries in recent years and upon arrival, found the abundance of food sources interesting, perhaps alluring, and in time, overpowering. Kamini's experience (a British migrant to New Zealand) offered a first-hand glimpse into the struggles of post-migration weight gain.

[When] I came to New Zealand in 2008, I was $79 \mathrm{~kg}$. [She is currently $109 \mathrm{~kg}$ ] ... We didn't really eat [any] kind of takeaway food-that was actually quite expensive ... [out here] we got the leaflets ... \$20 for three pizzas and fries and garlic bread. We were like, that's like 10 pounds [sterling] ... We lived in England there wasn't really that availability. (Kamini, F-38)

Her initial excitement of having easy access to processed foods, just a phone call away, and without a hefty price tag, died down over a couple of years, once she started noticing her increasing waistline. The ever-increasing mobility of populations across the world in recent years, either by choice (migration) or by force (seeking refuge), is certainly having an impact on migrant health status. ${ }^{27-30}$ The study 
participants also talked about another closely related issue of food and migration, but from the perspective of colonisation, that is, the movement of foreign food sources and its impact on the health of indigenous populations. Overwhelming new foods describe the migration of foods and the lasting impact it had on health and well-being, primarily for indigenous populations. Joann, a middle-aged Māori woman, protested against non-native foods, stating how she perceived them to be incompatible with the bodies of the indigenous population. She even debated whether the root cause of the Mãori (indigenous) obesity epidemic was due to the population's exposure to innately incompatible foreign foods. Introduction of foreign foods and its consequences for the health of indigenous populations has been a topic of interest for policymakers globally. ${ }^{31}$ Studies have shown these patterns to emerge out of events of colonisation, including the global food-aid programs designed to assist impoverish nations achieve food sustainability. ${ }^{32}$ This major process in fact aptly captured the multi-level mediators of obesity wherein exposure to unfamiliar food sources, by choice or by force, seemingly had an unfavourable impact on the participants' health and well-being. This status quo of obesity gave rise to feelings of vulnerability for many participants outlined next.

\section{3 | Feelings of vulnerability}

Feelings of vulnerability as a major process describe the sense of helplessness felt by individuals living with unhealthful weight, specified further by three sub-processes: food addiction, health care dependence and mediated stigmatisation.

Food addiction describes the addictive tendencies of certain food commodities that make it harder for individuals to curtail their consumption. Participants talked about their inability to control their food-based triggers (urges) to repeatedly seek and consume foods which were inherently loaded with sugar, salt and fat. Consciously avoiding exposure to such (addictive) foods only made matters worse, at times giving rise to feelings of withdrawal symptoms, akin to painful experiences. Food addiction has become a major concern for practitioners and policymakers alike in the fight to curtail the obesity epidemic. ${ }^{33,34}$ With the ever-increasing supply of processed and energy-rich food sources globally, the impact is felt far and wide. ${ }^{35-37}$ A few of the participants also narrated how the addictive qualities of food on offer led to weight gain which became an urgent health concern that forced them into a cycle of medical dependency. Health care dependence describes how participants were forced to seek multiple lines of treatments for obesity-related health issues. These sudden changes in health status made them feel unhappy, unhealthy and acutely vulnerable. Studies have shown the link between increasing rates of obesity and associated needs of health care service provisioning for reducing resultant morbidity. ${ }^{7,38}$ No one likes to be on this descending spiral of ill health and medical dependency.

These feelings of vulnerability extended beyond the acute needs of medical assistance wherein the excess bodyweight became a vanity issue, as described by mediated stigmatisation. Mediated stigmatisation highlighted ecologically mediated stigmatisation processes that make obese individuals feel vulnerable. Tammy, a young mother of two, described her experiences with unsupportive social commentary about her weight gain which sent her self-worth into an out-of-control downward tailspin.

Personally, it's a huge issue. I don't feel good. The clothes don't fit well ... So when I say that weight bothers me, it's very personal ... It's the society and the people and the comments that really make me go extremely unhappy ... I felt [feel] vulnerable and negative, and that basically puts me into a (downward) spiral. (Tammy, F-40)

Studies show that obesity has become a communal or societal challenge, and any resolution needs communal initiatives as well as community support. ${ }^{39,40}$ The mediated stigmatisation was not helping those in need of care and support from all sections of society. To summarise, all of the major processes discussed so far had elements of individual and ecological influences working in tandem, leading many participants to indulge in unhealthy food-related consumption choices and experience unhealthful weight gain. Findings also outlined three major processes with sub-process that contributed to these outcomes of obesity through ecological influences.

\subsection{Socio-cultural normativity}

Socio-cultural normativity processes are elaborated further by three sub-processes: social cohesion, obligatory group norms and cultural consumption norms. Social cohesion describes episodes of food-related consumption practices which go beyond satisfying hunger, wherein food is used to augment social cohesion and to enhance connectedness within families. Watty, a middle-aged business consultant, described his love of food and how his tendency to overconsume was mostly related to his socialising with friends and family.

I love food, absolutely love food ... I don't count my calories ... you know; we are going to a friend of mine's birthday down in Hamilton on the weekend. We are going to stay with my mum. My mum makes the most amazing meals; like, I don't even want to count my calories. It will be horrendous. (Watty, M-54)

The act of consuming food has individual, social and communal consequences, and at times the discourses go beyond the simple needs of satiation. ${ }^{10,41}$ Obligatory group norms are also connected to indulgent consumption and describes the social obligations (pressures) faced by the participants to take part in episodes of consumption, at times against their own wishes. Kamini talked about her experience of 
feeling ridiculed for non-participation at a social event where drinking alcohol was a group norm.

I went to a gathering that I got invited to ... People were drinking, and although I'd stated several times, "I'm fine with Coke; I'm fine with water," they kept pushing me, and every time they got the wine out it was like, "you don't want any, are you sure?" ... Look at us having a great time, and you're weird because you're not drinking. (Kamini, F-38)

Consumption norms led by peer pressure have been a topic of interest for scholars not only within the domains of food and obesity but also within substance abuse studies as well. ${ }^{42,43}$ It was not just social norms that played a role in food-related consumption practices of the study participants. Cultural norms also did. A few of the participants talked about how they were expected to take part in culturally appropriate cooking practices and to follow set patterns of food consumption norms. Research shows individuals growing up within cultures or sub-cultures; in fact, take pride in participating in associated cultural food norms. ${ }^{44,45}$ Any attempts to question these norms can and at times does result in social disharmony, an event very many would avoid at any cost. ${ }^{46}$

\section{5 | Pervasive food marketing}

Pervasive food marketing outlines the increasing influences of food marketing and its impact on the health and well-being of communities. Data analysis revealed three sub-processes within pervasive food marketing practices: self-promotive free will, dominant market forces and sponsored consumption norms. Self-promotive free will describes how the participants found it hard to believe when free-will ideologies were used by food manufacturers to openly pursue their economic agenda, all along promoting unhealthy foods. The pervasiveness of food marketing and its consequences for health and well-being of communities has been a topic of debate, research and discussion for more than two decades. ${ }^{47,48}$ It is not only seemingly pervasive but also increasingly becoming the dominant voice within the discourses of food-related consumption practices. Methy was "amused" at how multi-billion dollar campaigns run by food corporations were winning the battle for consumers' attention over the little-funded local campaigns that advocated healthy consumption practices.

You know, companies like the big chocolate companies and Coca-Cola have spent billions of dollars on advertising. The "5+ A Day" [government funded health promotion]-they've got like a million-dollar campaign or something, you know. When you look at the difference in how much money is spent on the advertising, it's phenomenal. (Methy, F-48)

Participants' narratives also suggested that institutionally promoted consumption discourses and ideologies were often very deviant in their motives, a feeling captured by sponsored consumption norms. A few of the participants readily pointed out how major sporting events around the world were increasingly co-sponsored by beverage companies, promoting products loaded with sugars and all kinds of alcohols, and how counterintuitive all of this was. They wondered how no one saw the disconnect between the promotion of sporting events for communal health and the promotion of sugar-laden foods by companies sponsoring events meant to uplift the health and well-being indices of the wider society. Studies have shown the roles played by product/ brand endorsements and their consequences for popular culture and associated consumption norms. ${ }^{49,50}$ Pervasive food marketing and its rapid growth in recent decades and its implications for societal health and well-being did not go unnoticed by the participants in this study.

\section{6 | Intervention setbacks}

Intervention setbacks outline some of the fundamental reasons why health-promotive intervention programs did not achieve the desired outcomes for many and are elaborated further by three sub-processes: unnatural routines, paternalistic ethos and transactional relationships. Unnatural routines describe a participant's inability to cope with a health care consultant's recommendations of altered lifestyle and food choices. Calvin described his 8-week engagement with a nutritionist who put him on a meal-replacement therapy. Despite a supportive home environment, he walked away from the intervention.

Yeah, so they put me on a liquid replacement diet ... plus low energy vegetables that they would allow you to eat in the evening, water, and it was pretty ruthless ... So all the choice was taken away. You knew you just had to have a banana shake or a chocolate shake or a vanilla shake and that was it. (Calvin, $M-60)$

Consumption norms and practices are an important part of who we are as individuals. ${ }^{2,51}$ Walking away from such deep-rooted consumption habits is a difficult endeavour, an element that is perhaps not accounted for when such changes are advocated by health care practitioners. ${ }^{6,52}$ Participants questioned health care pracitioners' demeanour as well as their recommendations for altered consumption behaviours. Paternalistic ethos describes the authoritarian nature of the relationship between the nutritionists guiding the intervention programs and the participants seeking assistance. Risina, a young Māori woman, described how her nutritionist approached the whole situation from a typical Pākehā (New Zealand European) perspective and was very authoritative in her demeanour.

Oh, we'll see, but I didn't go back, because she kept making comments about ... but why do you eat that ... I was just like because it was what I grew up on. I didn't feel like she had that cultural understanding ... I 
don't think she understood or handled it too well, so I didn't go back to her. (Risina, F-26)

The power distance between the health care service providers and the client, including the outcome of the relationship quality, has been a topic of interest in many studies. ${ }^{53,54}$ Not being treated as an equal partner who could co-create the outcomes of consultation can be the sources of frustration for many. ${ }^{55}$ Many participants also commented on the fact that most consultants they engaged with were very transactional in their approach. A consistent concern was how once the predetermined weight loss was achieved; the consultants ceased all contact and became increasingly distanced from providing further assistance. Clearly, attempts at building enduring relationships were missing for some of the participants, and this led to early termination of consultations and consequences of little or no improvement in health status.

\section{4 | DISCUSSION}

This study explored the multi-layered challenges associated with obesity management, predominantly for individuals engaging in various types of health care intervention programs. Becoming obese underlines a raft of processes, which work simultaneously through individual- and ecological-level influences to undermine an individual's ability to take control of their (food-related) consumption choices, as well as purposefully lead a healthy life (see Figure 1). The key is the sphere of control which could be exercised by each individual, and their ability to take remedial actions to minimise the potency of such influences acting upon them.
The current study outlined how individuals who are actively engaging with various intervention programs to remedy their (ill) health did not always get the desired outcomes. At an individual level, one of the first factors that stood out was the kinds of engagements and relationships individuals have with food, and the nature of access to those food sources. At one end of the continuum, it might be purely for the purposes of satiation of hunger, and on the other extreme, it might be for indulgence. Having the resources coupled with ready access to abundant foods on offer had a detrimental impact on health and well-being, but so did lack of resources to procure the right kind of foods (healthy vs unhealthy) and the consumption choices made thereafter. These facets of one's life have a bearing on how individuals are raised and on their relationship with food as nutrition, vs food as indulgence. All of these themes resulting from our study so far are fairly consistent with the extant literature. ${ }^{56,57}$ It must also be highlighted that this access at times may have been a result of people getting exposed to unfamiliar foods or surroundings led by international migration journeys made by them, either willingly or perhaps forcibly. Body's exposure to foreign foods (non-native) had an impact on the growing waistline of participants, results which were fairly consistent with current literature. ${ }^{27}$

Another crucial and perhaps abundantly important individual factor that emerged was that of food addiction. Participants routinely talked about their inability to control excessive consumption of addictive foods as being so painful that for many of them, surrendering to the addictive urges seemed an easier way out. We found a significant support within the literature describing the link between patterns of substance abuse and food addiction studies. ${ }^{35,37}$ In fact, the discussion on food addiction is very topical in today's times and is being looked at by many

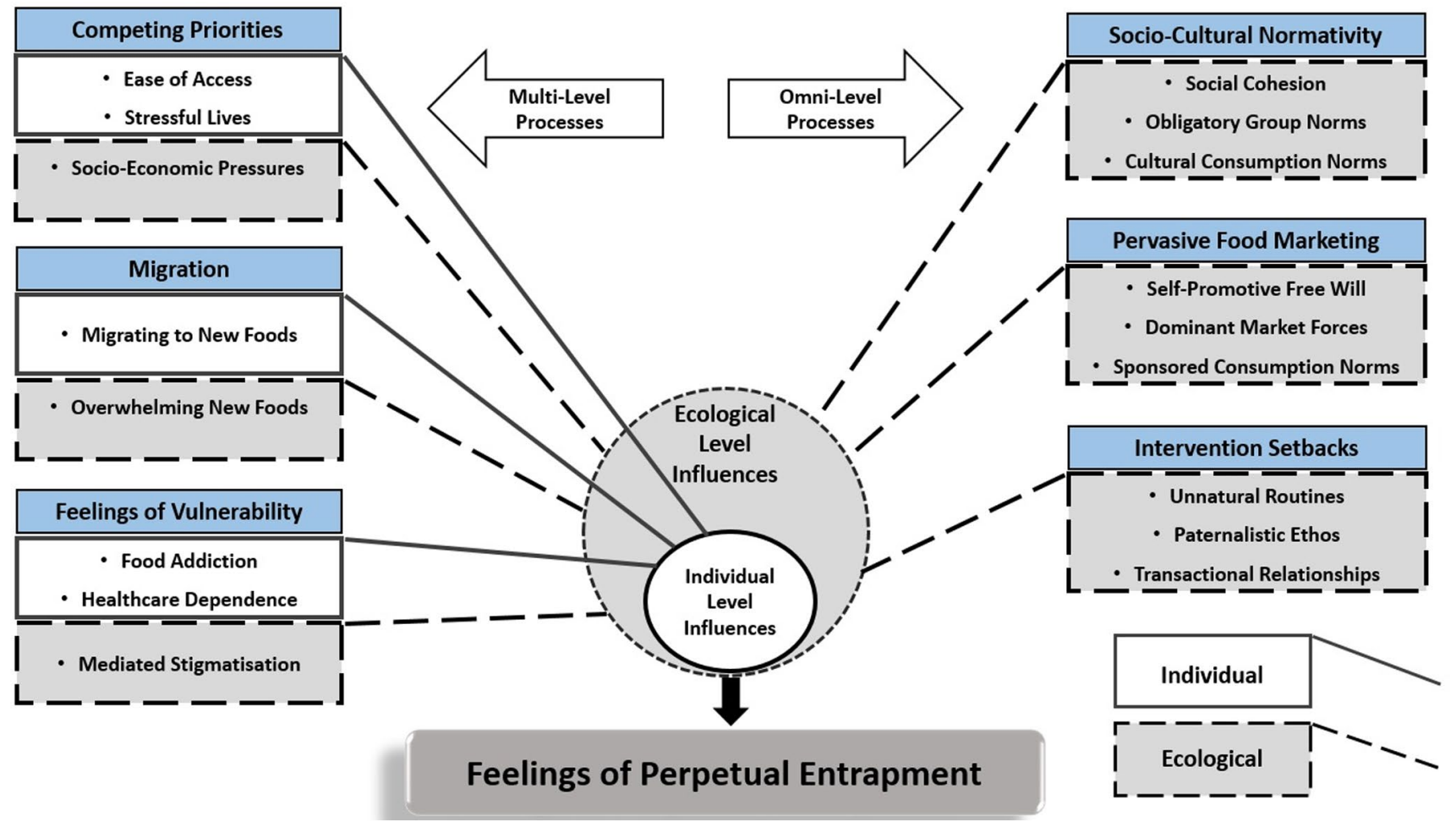

FIGURE 1 Individual and ecological level influencers of obesity 
as a possible research opportunity within the domains of obesity management. These addictive tendencies of certain foods when coupled with stressful life situations made for a perfect storm. Invariably the onus to take control, make healthy (lifestyle and consumption) choices is always put upon an individual (living with obesity). The routinely used proverb (in media) of "eat less and move more" seems an inherently simple and linear solution to a prodigious and non-linear problem.

During the conversations, many participants described how they had to learn to prioritise themselves and their own health over and above everything else; however, this was easier said than done. Studies talk of lack of time and its impact on health and well-being. ${ }^{58}$ This difficulty was further pronounced when an individual needed to manage various obligations at personal, social and professional levels which created a perfect storm of time-poor lifestyles, and depletion of the very resources one needs to look after oneself (time), culminates in the undesirable outcome of obesity. This lack of a key resource, that is time to look after oneself and its implications for obesity and well-being has support in the literature. ${ }^{59,60}$ All of these processes operational at an individual level eventuated into an out of control spiral for some of the participants who had to (unwillingly) engage with health care service provisioning to remedy their ill-health; which made them feel highly vulnerable and perhaps gave rise to feelings of entrapment.

Our findings also suggest individually mediated processes were working in tandem with ecologically mediated processes, which pronounced these feelings of entrapment for many. The lack of economic resources has a major impact on how individuals procure, process and consume foods. It does not mean they are not conscientious of the fact that they need to make the right (healthy) procurement choices, lack of resources remains a major stumbling block for health and wellness outcomes for many. ${ }^{61}$ It almost becomes a perpetual cycle(s) most cannot get out of, and get blamed for the resulting obesogenic outcomes as individuals who made "poor" consumption choices. Data show that these feelings of helplessness were not readily appreciated by other members of the community who instead chose to blame obese individuals for their lack of self-control. This mediated stigmatisation was so common (in participant narratives) that it gave rise to issues of self-doubt and body image, which occasionally led to depressive symptoms as well as to social seclusion. We found support for these outcomes within the current literature, particularly in community psychology and studies within the domains of feminism. ${ }^{60,62}$

There were processes, which exclusively acted (in-concert with others) via the ecologically mediated pathways. As evidenced by this study, food plays a major role in the social aspects of individuals' everyday lives beyond the primary need of hunger satiation. Food is also used to enhance a sense of belonging within the wider community, and to show inclusiveness towards cultural diversity of one's social life. This relationship between consumption and obesity is deeply ingrained in the socio-cultural fabric of contemporary communities and was evident in the existing literature. ${ }^{6,63}$ For many participants, the needs for social bonding outway the needs for health and well-being. Their non-participation attempts in socio-culturally driven consumption practices were either vilified to a varying degree or lead to episodes of social seclusion, which were not acceptable to many. ${ }^{63,64}$
The study also helped illustrate how ecologically acting pervasive food marketing strategies did no favours on those wishing to bring about a meaningful change in their diets and lifestyle choices. Almost all participants touched upon the sheer pervasiveness of institutionally driven food marketing campaigns in one way or another during their interviews. Their discussions focussed on how institutions had free rein over the markets, without ever being questioned about their real motives for promoting ideologies, which conveniently benefited them. The evidence points to the fact that the debate and or communal discourses were no longer about healthy vs unhealthy foods but instead had moved towards how tasty and how aesthetically appealing food needed to be. All of these themes discussed so far found substantial support within the literature. ${ }^{47,65}$ Food marketing has become a key concern for not just experts in health care sciences but for researchers in social sciences too. The calls for policy interventions are getting louder each year. ${ }^{66,67}$

A detailed discussion on weight management programs ensued in most of the interviews. One of the foremost concerns for the participants was how (various) weight management programs prescribed drastic, and at times, impractical changes in individual lifestyles, patterns of food consumption and behaviours. In the end, programs were perceived to be either too cumbersome or too tiring to follow through with, at which point many fell back into their old habits, resulting in further weight gain. Disengagement with weight management programs remains a concern for those offering such services. ${ }^{2,3,68}$ Issues were also raised about their dissatisfaction with the transactional nature of their relationships with the experts guiding them through interventional programs. For most, consultation episodes were intimate encounters that requiring them to confide in experts about issues that they would normally not even share with members of their own families. It was pointed out that the experts, however, routinely viewed these relationships as commercial engagements, where support was only available through sessions that were contractually binding and incurred fees. This transactional nature did not bode well with many. A routinely cited theme within the relationship management literature. ${ }^{69,70}$ Our study clearly demonstrates managing one's consumption choices and related health outcomes through the concomitantly acting influences is not an easy feat to achieve.

We suggest the time has come to conceive and offer a multi-layered solution to the obesity challenge. Based on the overall discussion, it is evident that not all of the complexities associated with weight gain could be resolved within the gambit of an individual consultant offering their services. Perhaps a team-based approach is needed wherein a team of professionals look after each individual needing assistance and design genuine wrap-around episodes of service provisioning.

\section{5 | CONCLUSION}

This study can and should be treated as a precursor to revisit and perhaps reconceive the current deployment(s) of interventional 
programs/strategies and its related outcomes. We would like to propose a more inclusive and possibly a comprehensive and holistic service design for future. At this juncture, we would like to offer a step-by-step guide to those wishing to take this new approach to interventional programs/strategies.

1. The first step would have to be building a team of like-minded and multi-skilled professionals who can offer multi-layered support provisioning to obese individuals needing assistance.

2. When meeting with potential clients for the first time, as part of the briefing session, perhaps identify some of their practice realities, that is individually and ecologically acting processes as narrated by them during the interview.

3. As part of the consultation process, explore these individually and ecologically acting processes a bit further for each individual seeking help.

4. Communicate the possible complexities associated with the clients' weight-gain history, and suggest solutions that could be offered by you, as well as other potential consultants within your professional network.

5. Insist the client meets with your team of professionals and understands that seeking assistance for resolving multitudes of issues that lead to obesity is the best way forward.

\section{ORCID}

Milind Mandlik (iD https://orcid.org/0000-0002-6452-1089

\section{TWITTER}

Milind Mandlik https://twitter.com/milindmandlik72

\section{REFERENCES}

1. Markets RA. Loss and weight management market by equipment, surgical equipment, diet, weight loss services-forecast to 2019 February. 2015 [cited 2015 Jul 25]. Available from http://www. researchandmarkets.com/research/xvpflx/weight_loss_and

2. Franz MJ, VanWormer JJ, Crain AL, Boucher JL, Histon T, Caplan W, et al. Weight-loss outcomes: a systematic review and meta-analysis of weight-loss clinical trials with a minimum 1-year follow-up. J Am Diet Assoc. 2007;107:1755-67.

3. Glasgow RE, Christiansen SM, Kurz D, King DK, Woolley T, Faber AJ, et al. Engagement in a diabetes self-management website: usage patterns and generalizability of program use. J Med Internet Res. 2011;13:e9. https://doi.org/10.2196/jmir.1391.

4. Gudzune KA, Doshi RS, Mehta AK, Chaudhry ZW, Jacobs DK, Vakil $\mathrm{RM}$, et al. Efficacy of commercial weight-loss programs: an updated systematic review. Ann Intern Med. 2015;162(7):501-12.

5. Moore ES, Wilkie WL, Desrochers DM. All in the Family? Parental roles in the epidemic of childhood obesity. J Consum Res. 2016;43(5):824-59.

6. Beruchashvili M, Moisio R, Heisley DD. What are you dieting for? The role of lay theories in dieters' goal setting. J Consum Behav. 2014;13(1):50-9.

7. Yach D, Stuckler D, Brownell KD. Epidemiologic and economic consequences of the global epidemics of obesity and diabetes. Nat Med. 2006;12(1):62-6.

8. Hamid TK. Thinking in circles about obesity: applying systems thinking to weight management. Heidelberg: Springer Science \& Business Media; 2009.
9. Wang YC, McPherson K, Marsh T, Gortmaker SL, Brown M. Health and economic burden of the projected obesity trends in the USA and the UK. Lancet. 2011;378(9793):815-25.

10. Wenk GL. Your brain on food: how chemicals control your thoughts and feelings. Oxford: Oxford University Press; 2014.

11. Ratcliffe D, Ellison N. Obesity and internalized weight stigma: a formulation model for an emerging psychological problem. Behav Cogn Psychother. 2015;43(2):239-52.

12. Mulugeta A, Zhou A, Power C, Hyppönen E. Obesity and depressive symptoms in mid-life: a population-based cohort study. BMC Psychiatry. 2018;18(1):297.

13. Butland B, Jebb S, Kopelman P, McPherson K, Thomas S, Mardell J, et al. Tackling obesities: future choices. Project report. Foresight tackling obesities: future choices Project report. 2007.

14. Butryn ML, Phelan S, Hill JO, Wing RR. Consistent self-monitoring of weight: a key component of successful weight loss maintenance. Obesity. 2007;15(12):3091-6.

15. Montesi L, El Ghoch M, Brodosi L, Calugi S, Marchesini G, Dalle GR. Long-term weight loss maintenance for obesity: a multidisciplinary approach. Diabetes Metab Syndr Obes: Targets Ther. 2016;9:37.

16. Dombrowski SU, Knittle K, Avenell A, Araujo-Soares V, Sniehotta FF. Long term maintenance of weight loss with non-surgical interventions in obese adults: systematic review and meta-analyses of randomised controlled trials. BMJ. 2014;348:g2646.

17. Panter-Brick C, Clarke SE, Lomas H, Pinder M, Lindsay SW. Culturally compelling strategies for behaviour change: a social ecology model and case study in malaria prevention. Soc Sci Med. 2006;62(11):2810-25.

18. Charmaz K. Constructing grounded theory. London: Sage; 2014.

19. Charmaz K. Constructing grounded theory: a practical guide through qualitative analysis. London: Sage Publication; 2006.

20. Lofland J, Lofland LH. Analyzing social settings. Belmont, CA: Wadsworth Publishing Company; 2006.

21. Drewnowski A, Darmon N. The economics of obesity: dietary energy density and energy cost. Am J Clin Nutr. 2005;82(1):265S-S273.

22. Whitaker RC, Wright JA, Pepe MS, Seidel KD, Dietz WH. Predicting obesity in young adulthood from childhood and parental obesity. $\mathrm{N}$ Engl J Med. 1997;337(13):869-73.

23. Hill SE, Prokosch ML, DelPriore DJ, Griskevicius V, Kramer A. Low childhood socioeconomic status promotes eating in the absence of energy need. Psychol Sci. 2016;27(3):354-64.

24. Öst A, Lempradl A, Casas E, Weigert M, Tiko T, Deniz M, et al. Paternal diet defines offspring chromatin state and intergenerational obesity. Cell. 2014;159(6):1352-64.

25. Dallman MF. Stress-induced obesity and the emotional nervous system. Trends Endocrinol Metab. 2010;21(3):159-65.

26. Pervanidou P, Chrousos GP. Stress and obesity/metabolic syndrome in childhood and adolescence. Int J Pediatr Obes. 2011;6(Suppl 1):21-8.

27. McDonald JT, Kennedy S. Is migration to Canada associated with unhealthy weight gain? Overweight and obesity among Canada's immigrants. Soc Sci Med. 2005;61(12):2469-81.

28. Boyle P, Norman P. Migration and health. In: Brown T, McLafferty $\mathrm{S}$, Moon G, editors. A companion to health and medical geography. Malden: John Wiley \& Sons, 2009; p. 346-74.

29. Borrell C, Muntaner C, Sole J, Artazcoz L, Puigpinos R, Benach J, et al. Immigration and self-reported health status by social class and gender: the importance of material deprivation, work organisation and household labour. J Epidemiol Community Health. 2008;62(5):e7.

30. Malmusi D, Borrell C, Benach J. Migration-related health inequalities: showing the complex interactions between gender, social class and place of origin. Soc Sci Med. 2010;71(9):1610-9.

31. Cassels S. Overweight in the Pacific: links between foreign dependence, global food trade, and obesity in the Federated States of Micronesia. Globalization Health. 2006;2(1):10.

32. Popkin BM. The world is fat. Sci Am. 2007;297(3):88-95 
33. Ifland JR, Preuss HG, Marcus MT, Rourke KM, Taylor WC, Burau K, et al. Refined food addiction: a classic substance use disorder. Med Hypotheses. 2009;72(5):518-26.

34. Liu Y, von Deneen KM, Kobeissy FH, Gold MS. Food addiction and obesity: evidence from bench to bedside. J Psychoactive Drugs. 2010;42(2):133-45.

35. Fortuna JL. The obesity epidemic and food addiction: clinical similarities to drug dependence. J Psychoactive Drugs. 2012;44(1):56-63.

36. Fraser S. Junk: overeating and obesity and the neuroscience of addiction. Addict Res Theory. 2013;21(6):496-506.

37. Davis C, Curtis C, Levitan RD, Carter JC, Kaplan AS, Kennedy JL. Evidence that 'food addiction' is a valid phenotype of obesity. Appetite. 2011;57(3):711-7.

38. Sassi F. Obesity and the economics of prevention. Paris: OECD; 2010.

39. Minkler M. Community organizing and community building for health. New Brunswick: Rutgers University Press; 2005.

40. Prilleltensky I, Prilleltensky O. Webs of well-being: the interdependence of personal, relational, organizational and communal well-being. In: Haworth J, Hart G, editors. Well-being: individual, community and social perspectives. London: Palgrave Macmillan UK, 2007; p. 57-74.

41. Sriram U, Morgan EH, Graham ML, Folta SC, Seguin RA. Support and sabotage: a qualitative study of social influences on health behaviors among rural adults. J Rural Health. 2018;34(1):88-97.

42. Hawkins JD, Catalano RF, Miller JY. Risk and protective factors for alcohol and other drug problems in adolescence and early adulthood: implications for substance abuse prevention. Psychol Bull. 1992;112(1):64.

43. Schlosser E. Fast food nation: the dark side of the all-American meal. Boston: Houghton Mifflin Harcourt; 2012.

44. Cairns K, Johnston J, MacKendrick N. Feeding the 'organic child': mothering through ethical consumption. J Consum. Cult. 2013;13(2):97-118.

45. Brulotte RL, Di Giovine MA. Edible identities: food as cultural heritage. London: Routledge; 2016.

46. Ashley B, Hollows J, Jones S, Taylor B. Food and cultural studies. London: Routledge; 2004.

47. Levitsky DA, Pacanowski CR. Free will and the obesity epidemic. Public Health Nutr. 2012;15(1):126-41.

48. Seiders K, Petty RD. Obesity and the role of food marketing: a policy analysis of issues and remedies. J Public Policy Mark. 2004;23(2):153-69.

49. Spry A, Pappu R, Bettina CT. Celebrity endorsement, brand credibility and brand equity. Eur J Mark. 2011;45(6):882-909.

50. Choi SM, Rifon NJ. It is a match: the impact of congruence between celebrity image and consumer ideal self on endorsement effectiveness. Psychol Mark. 2012;29(9):639-50.

51. Foster GD, Wyatt HR, Hill JO, McGuckin BG, Brill C, Mohammed $\mathrm{BS}$, et al. A randomized trial of a low-carbohydrate diet for obesity. N Engl J Med. 2003;348(21):2082-90.

52. Toomath R. Fat science: why diets and exercise don't work-and what does. Auckland: Auckland University Press; 2016.

53. Mandlik MA, Glynn M, Hyde K. Client contribution to professional service delivery: implications for relationship quality. N Z J Appl Bus Res. 2014;12(1):19.

54. Ouschan R, Sweeney J, Johnson L. Customer empowerment and relationship outcomes in healthcare consultations. Eur J Mark. 2006;40(9/10):1068-86.

55. Harrison T, Waite K. Impact of co-production on consumer perception of empowerment. Serv Ind J. 2015;35(10):502-20.

56. Neeley S. Influences on consumer socialisation. Young Consumers. 2005;6(2):63-9.

57. Ratzan SC. Health literacy: communication for the public good. Health Promot Int. 2001;16(2):207-14.

58. Cooper Z, Fairburn CG. A new cognitive behavioural approach to the treatment of obesity. Behav Res Ther. 2001;39(5):499-511

59. Moens E, Braet C, Bosmans G, Rosseel Y. Unfavourable family characteristics and their associations with childhood obesity: a cross-sectional study. Eur Eat Disord Rev. 2009;17(4):315-23.
60. Zellner DA, Loaiza S, Gonzalez Z, Pita J, Morales J, Pecora D, et al. Food selection changes under stress. Physiol Behav. 2006;87(4):789-93.

61. Larsen K, Gilliland J. A farmers' market in a food desert: evaluating impacts on the price and availability of healthy food. Health Place. 2009;15(4):1158-62.

62. Bordo S. Unbearable weight: feminism, Western culture, and the body. Berkeley: University of California Press; 2003.

63. Block LG, Grier SA, Childers TL, Davis B, Ebert JEJ, Kumanyika S, et al. From nutrients to nurturance: a conceptual introduction to food well-being. J Public Policy Mark. 2011;30(1):5-13.

64. Counihan C, Van Esterik P, editors. Food and culture: a reader. London: Routledge; 2012.

65. Madzharov AV, Block LG. Effects of product unit image on consumption of snack foods. J Consum Psychol. 2010;20(4):398-409.

66. Kraak VI, Rincón-Gallardo Patiño S, Sacks G. An accountability evaluation for the International Food \& Beverage Alliance's Global Policy on Marketing Communications to Children to reduce obesity: a narrative review to inform policy. Obes Rev. 2019;20:90-106.

67. Mozaffarian D, Angell SY, Lang T, Rivera JA. Role of government policy in nutrition-barriers to and opportunities for healthier eating. BMJ. 2018;13(361):k2426.

68. Lang A, Froelicher ES. Management of overweight and obesity in adults: behavioral intervention for long-term weight loss and maintenance. Eur J Cardiovasc Nurs. 2006;5(2):102-14.

69. FitzPatrick MPD. Trust and gender in patient-practitioner relationships. Doctoral dissertation, The University of Waikato; 2004

70. Finley CE, Barlow CE, Greenway FL, Rock CL, Rolls BJ, Blair SN. Retention rates and weight loss in a commertial weight loss program. Int J Obes. 2007;31:292-8.

\section{AUTHOR BIOGRAPHIES}

Milind Mandlik (B. Pharmacy, M Comm., M Phil, PhD) is a teaching fellow in marketing, at the School of Marketing, University of Auckland Business School. He recently received his PhD from the University of Waikato (New Zealand). Being a student of biological sciences he understands and explores human behaviour through physiological, sociological and psychological processes fascinated by the ever-changing intricacies of human behaviour and its influence on consumption choices. His research takes a transdisciplinary approach focusing on issues of conscientious consumption behaviours, health outcomes and well-being.

John G. Oetzel (Masters of Public Health, PhD) is a professor in the Waikato Management School. He uses community-based, participatory research, to collaboratively work with communities to address various health issues to improve health equity. His current work includes the collaborative development of intergenerational village with two Māori community organisations ( $\mathrm{He}$ Kāinga Pai Rawe) and positive ageing (Kaumātua Mana Motuhake Pōī). He contributes expertise in research design and evaluation and believes in the importance of collaborative design to ensure that the research/evaluation fits the context and needs of communities as well as to ensure interventions are culturally centred. His research collaborations have received more than $\$ 18$ million NZD funding and he is also the author of more than 120 articles/ book chapters and six books. 
Djavlonbek Kadirov (MSc, PhD) is a senior lecturer in marketing at the Victoria University of Wellington, New Zealand. He received his $\mathrm{PhD}$ in Marketing from the University of Waikato (New Zealand) and MSc in Marketing with distinction from Salford University (UK). Djavlonbek's research interests include marketing systems, marketing and society, sustainable marketing and authentic brands. His research has appeared in journals such as the Journal of Macromarketing, Journal of Marketing Management, Journal of Business Research and Consumption Markets \& Culture. Djavlonbek is the winner of the George Fisk Award for the Best Conference Paper at the 2013 Macromarketing Conference.
How to cite this article: Mandlik M, Oetzel JG, Kadirov D.

Obesity and health care interventions: Substantiating a multimodal challenge through the lens of grounded theory. Health Promot J Austral. 2020;00:1-11. https://doi.org/10.1002/ hpja.347 